\title{
Synergistic effect of tea tree oil on fungi causing vaginal thrush in pregnant women
}

\author{
Mariam T. Dahham Abd al Karim F. Omar* Batol I. Dheeb ** \\ Biology Department / College of Education for Women / University of Tikrit \\ *Department of Anesthesiology Techniques / University of Alqalam \\ ** Department of Pathological Analysis / College of Applied Sciences / University of Samarra \\ E-mail: Maryam.tarq1991@gmail.com
}

\begin{abstract}
Background: Vulvovaginal candidiasis(VVC), or Vaginal thrush, is a vaginitis caused by the overgrowth of some opportunistic yeasts of the genus Candida spp. Australian Tea Tree Oil (TTO) is one of the most important essential oils that contain many compounds that are effective against many bacteria and fungi, which may match the effect of common antibiotics.

Objective: The aim of this study was to isolate and diagnose fungi that causing vaginal thrush, in pregnant women and to study the effect of (pregnancy and pregnancy sequence and age) on the rate of infection compared to non-pregnant, as well as to study the drug sensitivity of isolates towards a number of antifungal and compared that with the inhibitory effectiveness of tea tree oil.

Material and Methods: 75 vaginal swabs from pregnant women and 50 from non-pregnant women were collected at ages ranging from 17-65 years. The isolates were diagnosed using several methods, including the Vitek2 Compact system. 17 isolates were selected to study the inhibitory effect of ten antifungal agents, six of them were automatically tested by the Vitek 2 compact system, which contains a sensitivity test kit (AST-YS07 Card). The essential oil (TTO) was analyzed by GC-MS to detect its content of active compounds. The inhibitory effect of TTO was studied according to "Broth dilution" method to determine minimum inhibitory concentration (MIC) for it, the inhibitory effect of four concentrations of TTO (100\%, $50 \%, 25 \%, 12.5 \%$ ) was also tested according to" well diffusion" method. This investigation also included a study of the mechanism of action (TTO).

RESULTS: The rate of infection among pregnant women was $(41 \%)$ with the highest rate of infection during the third trimester of pregnancy, while the percentage of non-pregnant women was only $8 \%$. Vaginal infection was also prevalent in the age group ranged between (17-29 years).The isolates showed resistance to (Ketoconazol, Terbinafine) while they were sensitive to (Nystatin, clotrimazol), as well as sensitive to all antifungal of (AST-YS07 Card). The analysis of the TTO using chromatogram showed that it contains 32 chemical compounds, most of them are monoterpene like (Terpinen-4-ol, 1, 8-Cineol). The MIC of TTO ranged between $(4-<2 \mu \mathrm{l} / \mathrm{ml})$. The function of TTO is to destroy the structural structure of the cell membrane and change its permeability, thereby leakage of cellular components and cell death.

Conclusion: Pregnancy increases the rate of vaginal candidiasis in women, especially during the third trimester. TTO is highly effective in inhibiting the growth of opportunistic candida yeasts.
\end{abstract}

Keywords: Candida, vaginal candidiasis (thrush), pregnancy, Vitek2 Compact, Antifungal, Tea tree oil.

\section{Introduction}

Vulvovaginal candidias (VVC) or vaginal thrush is vaginitis is also caused by the overgrowth of some opportunistic yeasts of the genus Candida spp due to local or systemic factors. Local inflammatory reaction resulting in vaginal candidiasis, which is the second most common vaginal infection after bacterial infection $[1,2]$. Women are at higher risk for this type of infection, and many studies have reported that about $75 \%$ of women will suffer from (VVC) at least once during their lifetime due to several factors including : pregnancy, genetic factors, high estrogen oral contraceptives, corticosteroid therapy, the use of over-the-counter antibiotics, diabetes, as well as HIV / AIDS [3,4]. C. albicans is the most common opportunistic colonizer of the vagina, responsible for most cases of (VVC) and is part of the normal flora of the human body, colonizing various anatomical sites such as the oral cavity, skin and vagina, in about $50 \%$ of a healthy member of the community without causing any health problems, but its presence is necessary for the host because it limits the spread of pathogenic fungi and thus enhances the immune system functions[5,6]. Many studies have shown that the incidence of vaginal candidiasis (VC) increases in women with pregnancy, especially during the last third, and this increase may be due to several reasons, the most important, change the pH of the vagina, increase the proportion of sugar in the vaginal secretions, and increase the level of estrogen During pregnancy it produces more glycogen in the vagina, which provides a good source of carbon necessary for the growth of Candida and germination, which leads to faster growth of yeast [7,8,9]. Azole is a fungistatic agents, and is considered the essence of treatment for vaginal thrush, but it is often associated with high 
toxicity to host tissues and drug resistance, as many studies have shown these drugs have a number of determinants such as their effectiveness and low solubility, so the search for natural products that are effective against Candida species has increased significantly recently [10,11]. The Australian Tea Tree Oil (TTO) is also known as Melaleuca oil, one of the most important essential oils containing many therapeutically effective compounds. It has been used medically in Australia for more than 80 years and is extracted from the Australian plant Melaleuca alternifolia by steam distillation [12,13]. Numerous studies have shown that antioxidant activity (TTO) against many bacteria and fungi is comparable to the effects of common antibiotics due to its content of many cyclic terpenes, such as Terpinen-4-ol and 1,8- Cineol and $\alpha$ pinen $[14,15,16,17]$.

\section{This study aimed to:}

1- Isolate and identification type of yeast that causing vaginal thrush in pregnant women.

2- Study the impact of pregnancy and the sequence of pregnancy and the age on the infection rates.

3- Study the inhibitory effect of antifungal on the isolates and to compare the inhibitory effect of the Australian tea tree oil (TTO).

4- Study mechanism of action of (TTO) in which it inhibits the growth of yeasts.

\section{Materials and methods}

Sampling: 125 vaginal swabs (VS) were collected during the period from October 1, 2018 to March 1, 2019 from the Women's Consultation of Salah al-Din General Hospital / Tikrit, and some private women's clinics in the city, including (75 VS) from pregnant women and (50 VS) from non-pregnant women. The age of women ranged from 17-65 years. The samples were transferred directly to the laboratory and transplanted on Sabouraud Dextrose Agar Medium (SDA). The plates were incubated at $37^{\circ} \mathrm{C}$ for $24-48$ hours $[18,50]$. The women were considered infected when the number of colonies in each implant per clinical sample was more than 10 colonies [31]. After isolation and purification, the samples were diagnosed according to the following methods :

1- Phenotypic characteristics and microscopic examination: After isolation on SDA medium and incubation at $37^{\circ} \mathrm{C}$ for 48 hours, the colors and shapes of the colonies growing on the medium were observed and examined under a microscope to observe the forms and sizes of yeast cells using the taxonomic keys [19]. The cells were then dyed with Gram's stain to reveal the dye-positive cells and to observe the forms of yeast cells and pseudohypha [20].

2- Test tube germination: $0.5 \mathrm{ml}$ of human serum was placed in sterile test tubes and then inoculated with a small part of a growing colony on the medium SDA and incubated at a temperature of $35-37^{\circ}$ $\mathrm{C}$ for a period of 2-4 hours, took a drop of suspended and examined microscopically under the X40 magnification to observe the presence of sprout-like cells in the form of a hand mirror, this test is used to distinguish C. albicans and C. dubliniensis.

3- Diagnosis of the isolates in differential medium HiCrome Candida Differential Agar: Is a selective medium works to isolate and develop yeast, and identify colonies belonging to the isolates of Candida and differentiate their types according to the form and color of colonies The test was conducted according to the instructions of the company equipped (HiMedia, India).

4- Vitek2 Compact Isolation Diagnosis: This test was carried out by the Vitek 2 Compact diagnostic system and is equipped with (BioMérieux, Marcy-l'Étoile, Franc), a fully automated diagnostic system based mainly on a range of biochemical reactions and which gave accurate results within hours [21].

Isolates sensitivity to a number of antifungal agents: The sensitivity of 17 isolates (including all isolated species) was tested for two antifungal groups, where the sensitivity of isolates to the first group of antifungal agents (Nystatin, Clotrimazole, Ketoconazole and Terbinafine) were tested by broth dilution method [22,23]. The second group of antifungal agents (Amphotericin B, Caspofungin, Fluconazole, Flucytosine, Micafungin, Voriconazole) were tested for isolation sensitivity completely by the Vitek 2 compact system, which includes an allergy test kit (AST-YS07 Card) which includes isolates sensitivity test for six types of antifungal and each specific concentrations distributed within the wells card where the result was read by the device after lap according to changes in turbidity after isolates growth [24].These antifungals were selected for the purpose of testing their effectiveness against isolates because it used in the therapeutic field against diseases caused by Candida spp. , they are commercially available and their prices are acceptable. 


\section{Tea Tree Oil (TTO)}

1- Analysis of essential oil of TTO and detection of its content of active compounds using gas chromatography (GC) connected to Mass Spectrometry: Determination the chemical composition of essential oil (TTO) that provided from (Tea Tree, Uk) was carried in the laboratories of the Department of Environment and Water / Environmental Research Center/Iraqi Ministry of Science and Technology by using GC -MS type (Shimadzu GC-2010 plus) according to the method recommended [25]. The components were determined according to GC-MS mass spectrometry interpretation using the National Institute of Standard and Technology (NIST) database with more than 62,000 known patterns and comparing the resulting spectrum of the unknown component with a range of known components stored at the (NIST) library.

2-Isolation Sensitivity Test for Tea Tree Oil (TTO): The inhibitory effect of tea tree oil on 17 isolates was studied by determining the lowest oil inhibitor concentration (MIC) according to the broth microdilution method [23], after dilution of the TTO by organic solvent Tween 80 (Sigma, USA) and by (1/1 volume) in order to increase the solubility of TTO and ease of mixing with the medium, a series of halves $(128,64,32$, $16,8,4,2)$ of the previous mixture (TTO + Tween80) were used in determining the MIC of oil. The sensitivity test was conducted according to the 'well diffusion' method (WD) according to [26, 27], where four concentrations of TTO were tested $(100 \%, 50 \%, 25 \%$ and $12.5 \%)$ and the effectiveness of each concentration was determined by measuring the diameter of the inhibition zone. If found, the inhibition zone is a Fungal growth free zone and the inhibition diameter above $12 \mathrm{~mm}$ was considered an indication of the high efficacy of the tested antibiotic [28].

3-Detection of the mechanism of the action of the Tea Tree oil (TTO) as an antifungal: The mechanism of the action of the TTO against Candida spp. was studied in according to [29,30], by treating yeast cells at slightly higher concentrations of minimum inhibitory oil concentration for $1-4$ hours, then assessing changes in membrane permeability through measuring leachate absorption (treatment solution after filtering cells) and comparing it to control samples (treatment solution without yeast cells), where the increase in absorption values express the leached cellular components that absorb light at a wavelength of $260 \mathrm{~nm}\left(\mathrm{OD}_{260}\right)$ and over varying periods of time.

Statistical analysis: Statistical analysis was conducted using the Minitab (version 17) software, using ChiSquare and F-test, where the averages were compared with Duncan's Multiple Range Test (DMRT).

\section{Results and Discussion}

The results showed that (35) vaginal swabs (28\%), of (125) swabs showed a positive result of laboratory implantation compared to (90) swabs (72\%) showed a negative result, and this may be due to the great similarity in clinical symptoms between Vaginal candidiasis and bacterial vaginosis that leading to a negative result of laboratory implantation is not consistent with the clinical diagnosis.

The relationship between vaginal candidiasis and pregnancy: The infections rates among the pregnant women were significantly higher than the non-pregnant women, this result agreed with [9]. During pregnancy, the vagina is more sensitive and susceptible to infection, this may be due to decreased immunity in pregnant women for a long time, as well as, pregnancy hormones is increased levels of glycogen in vaginal secretions during pregnancy,that play a role in changing the microbial community of the vagina and promote colonization by Candida.

Table (1-1): Percentages of Infection in Pregnant and Non-Pregnant Women

\begin{tabular}{|c|c|c|c|c|}
\hline \multirow[t]{2}{*}{ Category } & \multirow[t]{2}{*}{ the number } & \multirow[t]{2}{*}{$\%$} & \multicolumn{2}{|c|}{$\begin{array}{c}\text { Number and percentage of positive swabs for laboratory } \\
\text { transplantation }\end{array}$} \\
\hline & & & Number & $\%$ \\
\hline Pregnant & 75 & $60 \%$ & 31 & $41.3 \%$ \\
\hline Non-pregnant & 50 & $40 \%$ & 4 & $8 \%$ \\
\hline Total & 125 & $100 \%$ & 35 & $28 \%$ \\
\hline & & Chi-Sqt & .534 P-Value $=0.00$ & \\
\hline
\end{tabular}


The relationship between infection and pregnancy sequence: The results showed that the highest rate of infection with (VVC) in the pregnant group was during the third trimester of pregnancy (7-9 months). This result was consistent with other investigations [32,33] that showed that the vagina becomes less acidic and less able to fight infection.

Table (1-2): Percentage of infection among pregnant women according Pregnancy Sequence

\begin{tabular}{|c|c|c|}
\hline \multirow{2}{*}{$\begin{array}{c}\text { Pregnancy } \\
\text { Sequence }\end{array}$} & \multicolumn{2}{|c|}{$\begin{array}{c}\text { Number and incidence rates among pregnant women according to the sequence of } \\
\text { pregnancy }\end{array}$} \\
\cline { 2 - 3 } & the number & $9.8 \%$ \\
\hline$(0-3)$ & 3 & $\mathbf{6 . 4 \%}$ \\
\hline$(4-6)$ & 2 & $\mathbf{8 3 . 8 \%}$ \\
\hline$(7-9)$ & 26 & $\mathbf{1 0 0 \%}$ \\
\hline Total & 31 & $* *$ \\
\hline \multicolumn{2}{|c|}{ Chi-Square $=\mathbf{5 3 . 5 1 6 ~ P - V a l u e ~}=\mathbf{0 . 0 0 0 9}$} \\
\hline
\end{tabular}

The relationship between injury and age group: The highest rate of infection was in the age group between (17-29 years), where the rate of infection was $64.5 \%$, while the lowest rate of infection was in the age group between (40-50 years), where the rate of infection was $6.4 \%$. These results were clearly demonstrated in Tables (1-3), and the results were agreed with results of other researchers [34,35],which indicated that women in this age group are at the peak of their reproductive years and sexual activity, and most of them use oral (drug) or uterine contraceptives, which puts them at greater risk of infection than others.

Table (1-3): Percentages of infection according age group

\begin{tabular}{|c|c|c|c|c|c|}
\hline \multirow{2}{*}{$\begin{array}{c}\text { Age Group } \\
\text { (Year) }\end{array}$} & Pregnant & $\%$ & Non-pregnant & $\%$ & Total \\
\cline { 2 - 6 } & 20 & $64.5 \%$ & 2 & $50 \%$ & 22 \\
$30-39$ & 9 & $29 \%$ & 1 & $25 \%$ & 10 \\
$40-49$ & 2 & $6.4 \%$ & 1 & $25 \%$ & 3 \\
\hline \multicolumn{6}{|c|}{ Ch } \\
\hline \multicolumn{7}{|c|}{ Chi-Square = 1.561 P-Value $=\mathbf{0 . 4 6 2}$} \\
\hline
\end{tabular}

Cultural Characteristic: The isolates developed on the medium of the solid Sabouraud dextrose agar (SDA) appeared in the initial isolation, in the form of white to cream-colored colonies, circular, convex, smooth butyrous texture. With the exception of four isolates, dry, wrinkled colonies with pale white edges were shown. These qualities were identical to those of yeasts demonstrated by [36] and Figure (1-1) illustrated the shape of the colonies.

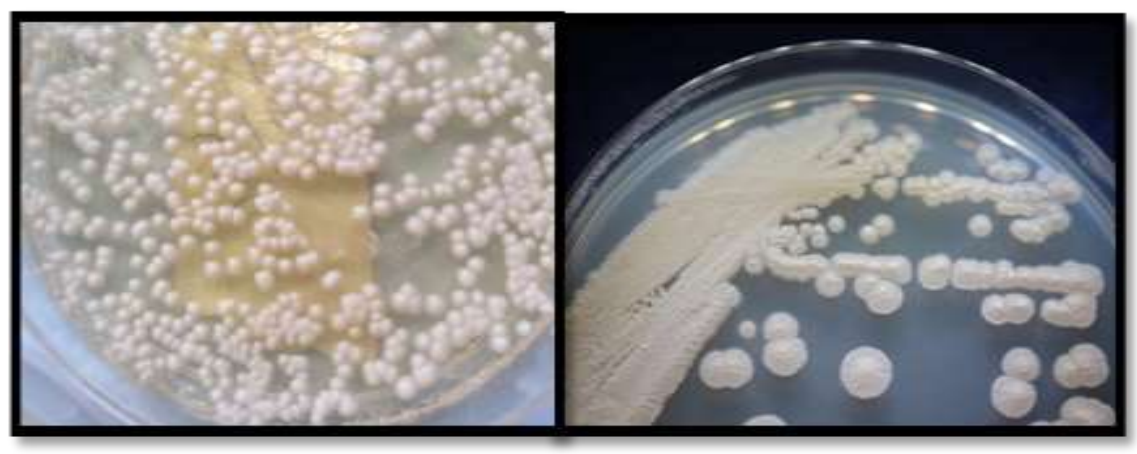

Figure (1-1): Forms of growing Khmer colonies on Sabouraud Dextrose Agar medium (SDA) for 48 hours at $37^{\circ} \mathrm{C}$ 
Microscopy: Yeast isolates were examined microscopically after staining with methyl blue and Gram stain, where the yeast cells appeared spherical to oval or elongated, budding and different sizes. The presence of pseudohypha and blastospores. All the isolates showed a positive result of the Gram stain, these are the characteristics of the yeasts shown by [37].

Germination tube test: (22) isolates showed positive result of this test among (34) isolates really (62.8\%), while (13) isolates showed negative result of the test (37.1\%). Growing cells were observed in a mirror-like manner as described [38] and illustrated in the Figure (1-2).

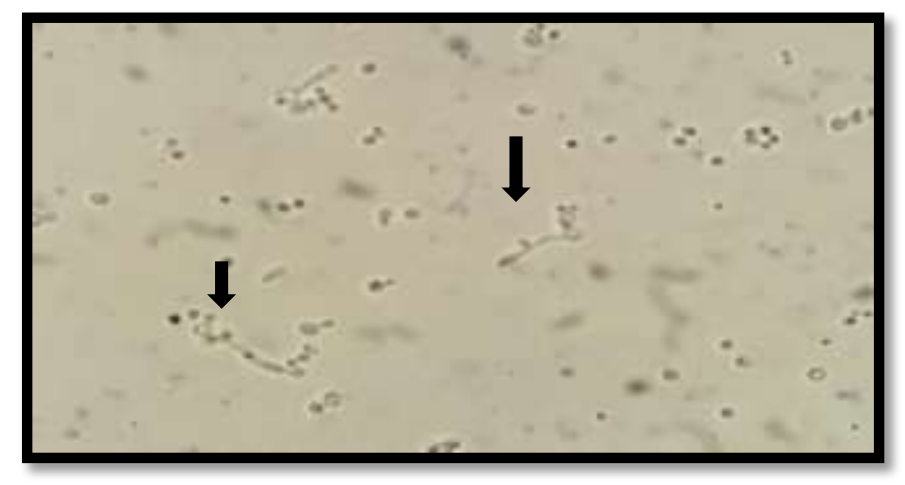

Figure (1-2): Formation of germination tube (indicator) of a growing yeast cell in human serum $(40 \mathrm{x})$

Relationship between infection and isolated species: The results of the diagnosis showed that (7) species belonging to the genus Candida spp., and specifically type $C$. albicans ranked first among the isolated species, where the number of isolates (26) isolation of the total (35) isolation, or by (74.2\%), while the proportion of other species combined (20\%), Figures (1-3) shows that the isolated species and their percentages. This result was consistent with other study [31, 27]

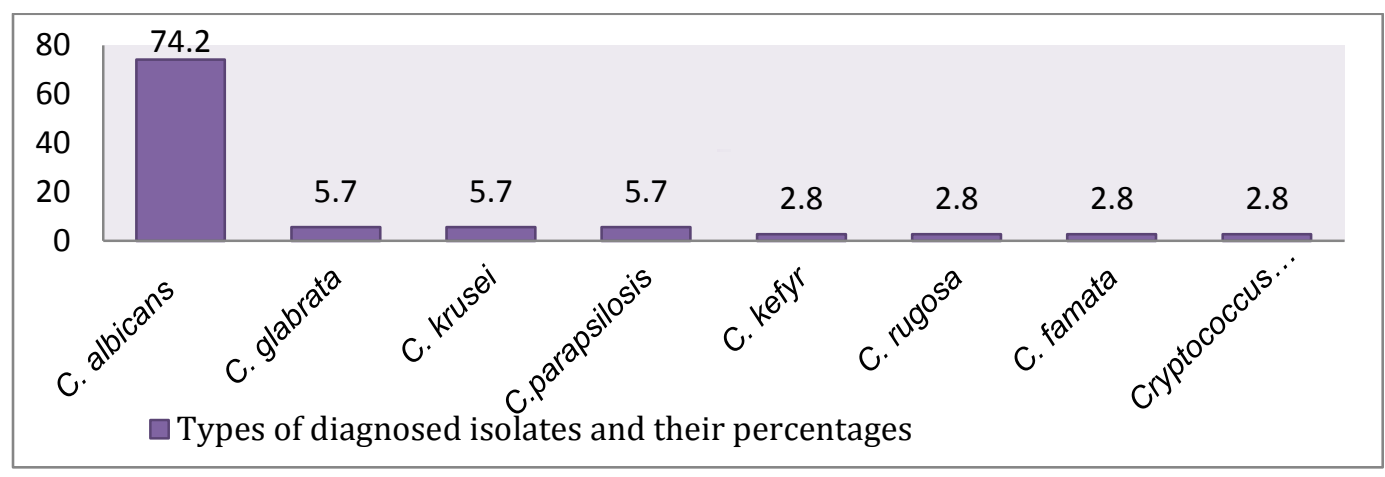

Figure (1-3): Types of diagnosed isolates and their percentages

\section{Drug sensitivity test for isolates against a number of antifungal agents}

1- Broth dilution method: The results showed that Nystatin was the most effective on the isolated with MIC (2-16 $\mu \mathrm{g} / \mathrm{ml})$. Clotrimazol was the second most effective with MIC (>0.5-8 $\mu \mathrm{g} / \mathrm{ml})$. Furthermore ,the results showed that only four isolates were resistant, while most of the isolates showed clear resistance to Ketoconazol and Terbinafine with MIC $(8-64 \mu \mathrm{g} / \mathrm{ml})$ and $(16-128 \mu \mathrm{g} / \mathrm{ml})$ respectively. The results were consistent with other study ,ki797[27], and disagreed with [39]. The difference in the identification of MIC antifungal between different studies may be due to the difference in the therapeutic efficiency of antifungal by different manufacturers. It can also be due to the widespread and indiscriminate use of antifungals leading to differences in sensitivity between species within the same genus, as well as within the same species, this could allowed to emerge of new genotypes which were different than wild strains[40,41].

2- Vitek2 Compact Sensitivity Test: The results of this test showed that most of the isolates under test were sensitive to the group of antifungal included in the test card (AST-YS07 Card) and some of them showed 
moderate sensitivity with a slight increase in the MIC values of some antifungal by non-albicans candida species (NACsp). as shown in Table (1-4).

Table (1-4): Sensitivity of Isolates to Some antifungal and minimum inhibitory concentration by Vitek2 Compact System

\begin{tabular}{|c|c|c|c|c|c|c|c|}
\hline \multirow[t]{2}{*}{ Isolation } & \multirow[t]{2}{*}{ Number } & \multicolumn{6}{|c|}{$\begin{array}{l}\text { The sensitivity of the isolates towards some antifungals and their minimum inhibitory } \\
\text { concentration (MIC } \mu \mathrm{g} / \mathrm{ml})\end{array}$} \\
\hline & & $\mathbf{A B}$ & CAS & FLU & FCT & MCF & VRC \\
\hline C. albicans & 10 & $1-0.25=>$ & $<=0.25$ & $8-<=1$ & $16-<=1$ & $0.12-<=0.06$ & $0.25-<=0.12$ \\
\hline C. glabrata & 2 & 1-0.5 & $<=0.25$ & 4 & $<=1$ & $<=0.06$ & $<=0.12$ \\
\hline C. kefyr & 1 & 0.5 & $<=0.25$ & $<=1$ & $<=1$ & 0.12 & $<=0.12$ \\
\hline C. rugosa & 1 & 2 & $<=0.25$ & 16 & 16 & 0.12 & $<=0.12$ \\
\hline C. krusei & 1 & 2 & $<=0.25$ & 16 & 16 & 0.12 & $<=0.12$ \\
\hline c. parapsilosis & 1 & 2 & $<=0.25$ & 16 & 16 & 0.12 & 0.25 \\
\hline C. famata & 1 & 2 & $<=0.25$ & 16 & 16 & 0.12 & $<=0.12$ \\
\hline
\end{tabular}

- AB: Amphotericin B, CAS: Caspofungin, FLU: Fluconazole

- FCT: Flucytosine, MCF: Micafungin, VRC: Voriconazole

- Blue color means that the isolates are moderately sensitive to the anti-inermediate.

- Lack of blue color means that isolates are sensitive to susceptible

\section{Tea Tree oil (TTO)}

Tea Tree oil analysis: The chromatogram of the TTO showed that it contains 32 chemical compounds, mostly monoterpene and sesquiterpene, which represented about $90 \%$ of the chemical composition of the oil. The main component of the essential oil under study is (1,8-Cineol). It constituted $67.2 \%$ of the total area of the essential oil chromatogram. Followed by the compound (Terpinen-4-ol), which constituted an area of $(6 \%)$ as well as oil contains varying proportions of ( $\alpha$-pinen, $\gamma$-Terpinen, Terpinolen, Champhor, Limonene dioxide, $\alpha$-terpineol). Considerable attention was given to any of the components of TTO responsible for antimicrobial activity. Early indications were that most of the activity could be attributed to terpinen-4-ol and $\alpha$-terpineol [42]. Data available today confirm that these two components contribute significantly to antibacterial and antifungal activities in oil [43,44]. Hammer et al. [30] also demonstrated that 1,8-Cineol and terpinen-4-ol increase the permeability and fluidity of the membrane, which may form the basis of tea tree oil. He also pointed out that many components of TTO share the anti-oil effect, but differ in their patterns of action against yeasts and that TTO has several mechanisms of antifungal action, which need more studies to understand it clearly [30].

Determination of Minimum Inhibitory Concentration (MIC) of Tea Tree Oil (TTO): The results showed a clear effect of (TTO) on all isolates included the test and MIC ranged between ( $4-<2 \mu \mathrm{l} / \mathrm{ml})$ and without statistical significant differences in different species sensitivity. These results are agreed with other markers $[40,14]$.

Isolation sensitivity test to tea tree oil by well diffusion method: Tea tree oil has shown an inhibitory effect of yeast growth of all isolated Candida spp. that included in the test without exception, Table (1-5) and Figure (1-4) representing these results.. These results are agreed with [40,45]. 
Table (1-5): Effect of Tea Tree Oil (TTO) on Candida Genus under Study by 'well diffusion' method (WD)

\begin{tabular}{|c|c|c|c|c|c|}
\hline \multirow[t]{2}{*}{ Isolates } & \multicolumn{4}{|c|}{ Inhibition Diameter Rates (mm) } & \multirow[t]{2}{*}{ Cont+ } \\
\hline & $100 \%$ & $50 \%$ & $25 \%$ & $12.5 \%$ & \\
\hline C. albicans & $\begin{array}{c}15 \\
\mathbf{a E}\end{array}$ & $\begin{array}{c}11 \\
\text { bF }\end{array}$ & $\begin{array}{l}12 \\
\text { Bd }\end{array}$ & $\begin{array}{r}10 \\
\text { bD }\end{array}$ & 0.0 \\
\hline C. albicans & $\begin{array}{c}22 \\
\mathrm{aCD}\end{array}$ & $\begin{array}{c}14 \\
\text { bDE }\end{array}$ & $\begin{array}{c}15 \\
b B C\end{array}$ & $\begin{array}{c}15 \\
\text { bAB }\end{array}$ & $\mathbf{0 . 0}$ \\
\hline C. albicans & $\begin{array}{c}27 \\
\mathbf{a B}\end{array}$ & $\begin{array}{c}17 \\
\text { bcABC }\end{array}$ & $\begin{array}{r}19 \\
\text { bA }\end{array}$ & $\begin{array}{c}15 \\
\text { cAB }\end{array}$ & $\mathbf{0 . 0}$ \\
\hline C. albicans & $\begin{array}{l}37 \\
\mathbf{a A}\end{array}$ & $\begin{array}{c}16 \\
\text { bcBCD }\end{array}$ & $\begin{array}{l}18 \\
\text { bA }\end{array}$ & $\begin{array}{c}15 \\
\text { cAB }\end{array}$ & 0.0 \\
\hline C. albicans & $\begin{array}{c}24 \\
\mathrm{aBC}\end{array}$ & $\begin{array}{c}18 \\
\text { bAB }\end{array}$ & $\begin{array}{l}19 \\
\text { bA }\end{array}$ & $\begin{array}{c}15 \\
\text { cAB }\end{array}$ & $\mathbf{0 . 0}$ \\
\hline C. albicans & $\begin{array}{c}20 \\
\text { aCD }\end{array}$ & $\begin{array}{c}18 \\
\text { abAB }\end{array}$ & $\begin{array}{c}19 \\
\text { abA }\end{array}$ & $\begin{array}{r}17 \\
\text { bA }\end{array}$ & $\mathbf{0 . 0}$ \\
\hline C. glabrata & $\begin{array}{c}18 \\
\text { aDE }\end{array}$ & $\begin{array}{c}15 \\
\text { bCDE }\end{array}$ & $\begin{array}{c}13 \\
\text { bcCD }\end{array}$ & $\begin{array}{c}11 \\
\text { cCD }\end{array}$ & 0.0 \\
\hline C. glabrata & $\begin{array}{c}24 \\
\mathrm{aBC}\end{array}$ & $\begin{array}{r}19 \\
\text { bA }\end{array}$ & $\begin{array}{c}17 \\
\text { bcAB }\end{array}$ & $\begin{array}{c}15 \\
\text { cAB }\end{array}$ & $\mathbf{0 . 0}$ \\
\hline C. albicans & $\begin{array}{c}28 \\
\mathbf{a B}\end{array}$ & $\begin{array}{c}16 \\
\text { cBCD }\end{array}$ & $\begin{array}{r}19 \\
\text { bA }\end{array}$ & $\begin{array}{c}17 \\
\text { bcA }\end{array}$ & 0.0 \\
\hline C. kefyr & $\begin{array}{l}40 \\
\mathrm{aA}\end{array}$ & $\begin{array}{r}19 \\
\text { bA }\end{array}$ & $\begin{array}{c}17 \\
\text { bAB }\end{array}$ & $\begin{array}{c}13 \\
\text { cBC }\end{array}$ & 0.0 \\
\hline C. albicans & $\begin{array}{r}27 \\
\mathbf{a B}\end{array}$ & $\begin{array}{c}15 \\
\text { cCDE }\end{array}$ & $\begin{array}{r}18 \\
\text { bA }\end{array}$ & $\begin{array}{c}16 \\
\text { bcA }\end{array}$ & $\mathbf{0 . 0}$ \\
\hline C. rugosa & $\begin{array}{l}39 \\
\text { aA }\end{array}$ & $\begin{array}{c}16 \\
\text { bBCD }\end{array}$ & $\begin{array}{c}14 \\
b C D\end{array}$ & $\begin{array}{c}11 \\
\text { cCD }\end{array}$ & $\mathbf{0 . 0}$ \\
\hline C. krusei & $\begin{array}{c}24 \\
\mathrm{aBC}\end{array}$ & $\begin{array}{c}15 \\
\text { cCDE }\end{array}$ & $\begin{array}{r}18 \\
\text { bA }\end{array}$ & $\begin{array}{c}16 \\
\text { bcA }\end{array}$ & $\mathbf{0 . 0}$ \\
\hline C. albicans & $\begin{array}{c}22 \\
\mathrm{aCD}\end{array}$ & $\begin{array}{c}14 \\
\text { cDE }\end{array}$ & $\begin{array}{c}\mathbf{1 7} \\
\text { bAB }\end{array}$ & $\begin{array}{c}16 \\
\text { bcA }\end{array}$ & $\mathbf{0 . 0}$ \\
\hline C. albicans & $\begin{array}{c}19 \\
\text { aDE }\end{array}$ & $\begin{array}{c}13 \\
\text { bEF }\end{array}$ & $\begin{array}{c}15 \\
b B C\end{array}$ & $\begin{array}{l}10 \\
\text { cD }\end{array}$ & $\mathbf{0 . 0}$ \\
\hline C. parapsilosis & $\begin{array}{c}18 \\
\mathrm{aDE}\end{array}$ & $\begin{array}{l}11 \\
\text { cF }\end{array}$ & $\begin{array}{c}14 \\
b C D\end{array}$ & $\begin{array}{c}11 \\
\mathrm{cCD}\end{array}$ & $\mathbf{0 . 0}$ \\
\hline
\end{tabular}

- Similar capital letters in one column mean that there are no statistical differences between them

- Horizontally similar lowercase letters mean that there are no statistical differences between them

- Each transaction represents an average of three replicates per replicate one dish.

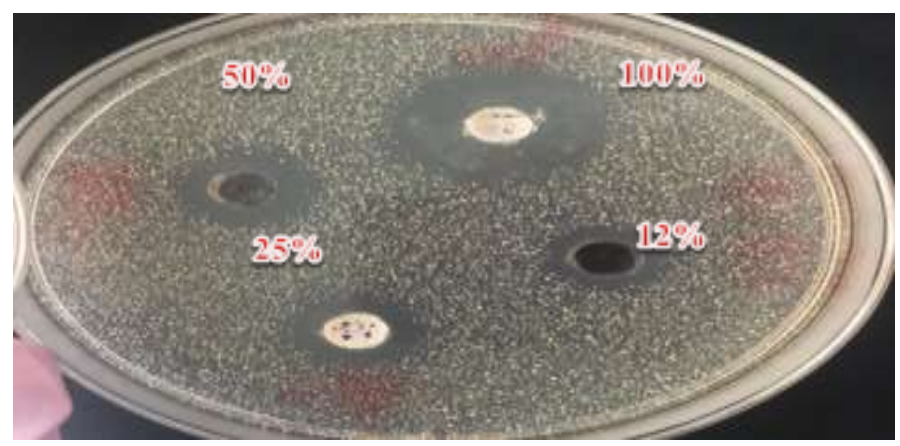

Figure (1-4): Inhibitory effect of four concentrations of TTO $(100 \%, 50 \%, 25 \%, 12.5 \%)$ on candida albicans 
Detection of the mechanism of action of tea tree oil (TTO) as an antifungal: The results of the statistical analysis showed that there are significant differences between the absorption values of the treatments recorded during the time periods (0,120 and 240 minutes) $)$ in comparison with the control sample. Increased absorption values were observed as the treatment time increased (Figure 1-5). It is believed that the increase in $\left(\mathrm{OD}_{260}\right)$ values is due to the leakage of cellular components of treated yeast cells, which absorb light at 260 $\mathrm{nm}$ wavelength, as a result of the destruction of the membrane structure and its increased permeability. Which is one of the most effective compounds involved in the structure of (TTO), where Terpenes (especially cyclic monoterpenes) due to their lipophilic nature, tend to interfere between the chains of fatty acyl that is composed of membrane lipid bilayers, which leads to stretch the membrane and increases its permeability then destroy it $[46,30,47]$. The result agreed with many of the results of similar studies, including [30,48,49] .

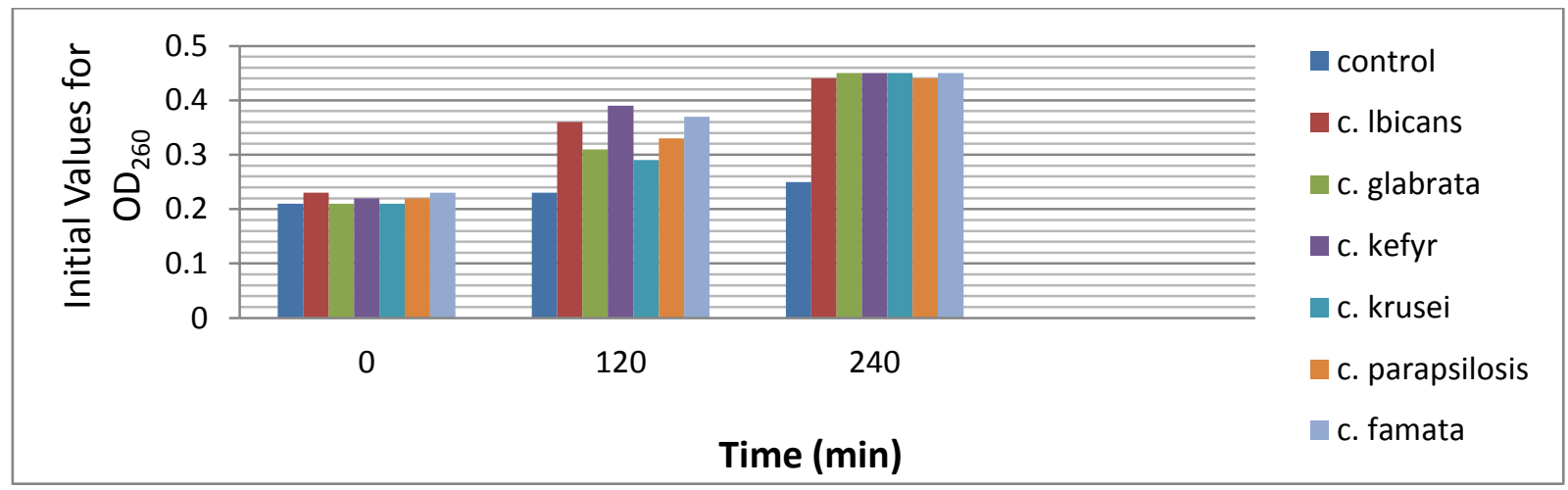

Figure (1-5): Increase in Absorption Values $\left(\mathrm{OD}_{260}\right)$ of the treatments filtration In comparison with Control Sample $(\mathbf{p}<0.05)$

\section{References}

1. Badiee P, Kordbachev P, Alborzi A, Malekhoseini S, Ramzi M, Mirhendi H, et al. Study on invasive fungal infections in immunocompromised patients to present a suitable early diagnostic procedure. Int $\mathrm{J}$ Infect Dis. (2009); 13: 97-102.

2. Segal E, Frenkel M. Experimental in vivo models of candidiasis. J.Fungi. (2018); 4(1): article number:21.

3. Bitew A , Abebaw Y. Vulvovaginal candidiasis: species distribution of Candida and their antifungal susceptibility pattern. BMC Women's Healthvolume. (2018); 18: Article number: 94.

4. Al-Tekreeti AR, Al-Halbosiy MMF, Dheeb BI, Hashim AJ, Al-Zuhairi AFH. Molecular identification of clinical Candida isolates by simple and randomly amplified polymorphic DNA-PCR. Arab J. Sci. Eng. (2017); DOI 10.1007/s13369-017-2762-1.

5. Beigi R, Meyn L, Moore D. Vaginal yeast colonization in non-pregnant women: a longitudinal study. Obstet. Gynecol. (2004); 104: 926- 930.

6. Brunke S, Hube B. Two unlike cousins: Candida albicans and C. glabrata infection strategies. Cell Microbiol. (2013); 15:701-708.

7. Akinbiyi A, Watson R, Feyi P. Prevalence of Candida albicans and bacterial vaginosis in asymptomatic pregnant women in South Yorkshire, United Kingdom Outcome of a prospective study. European. J.Obstetrics. Gynecol.Reproduc. Biol. (2009); 144(1): 68-71.

8. Ray D, Goswami R, Banerjee U, et al. Prevalence of Candida glabrata and its response to boric acid vaginal suppositories comparison with oral fluconazole in patients with diabetes and vulvovaginal candidiasis. Diabetes Care. (2007); 30(2):312-317.

9. AL tayyar IA, Al sanosi AS, Osman NA. Prevalence of vaginal candidiasis among pregnant women attending different gynecological clinic at south Libya. European. Journal of Experimental Biology. (2016); 6(3):25-29. 
10. Jacob MR , Walker LA. Natural products and antifungal drug discovery. Methods Mol Med. (2005); 118, $83-109$.

11. Cleveland AA, Harrison LH, Farley MM, et al. Declining incidence of candidemia and the shifting epidemiology of Candida resistance in two US metropolitan areas, 2008-2013: results from populationbased surveillance.(2015); PLOS ONE 10:e0120452.

12. Holliday and Ivan. Melaleucas: a field and garden guide (2nd ed.). Frenchs Forest, N.S.W.: Reed New Holland Publishers. (2004); 16-17.

13. Baskorowati L. Controlled pollination methods for Melaleuca alternifolia (Maiden \& Betche) Chee!. Canberra, ACIAR Techoical Reports No. 63. (2006).

14. Mertas A, Garbusińska A, Szliszka E, et al. The influence of tea tree oil (Melaleuca alternifolia) on fluconazole activity against fluconazole-resistant Candida albicans strains. BioMed Research International. (2015), V 2015, Article ID 590470, 9 pages.

15. Humphrey EM. A new Australian germicide. Medical Journal of Australia. (1930); 1: 417-428.

16. Hammer KA, Carson CF \& Riley TV. Melaleuca alternifolia (Tea Tree) oil inhibits germ tube formation by Candida albicans. Medical Mycology. (2000); 38: 355-362.

17. Mondello F, Bernardis FD, Girolamo A, et al. In vitro and in vivo activity of tea tree oil against azolesusceptible and -resistant human pathogenic yeasts. Journal of Antimicrobial Chemotherapy (2003); 51, $1223-1229$.

18. Gravina HG, Morán EG, Zambrano $\mathrm{O}$, et al. Oral Candidiasis in children and adolescents with cancer. Identification of Candida spp. Med Oral Patol Oral Cir Bucal. (2007); 1:12(6):419-423.

19. Morello JA, Granato PA, Mizer HE.Laboratory Manual and Workbook in Microbiology Application to Patient Care 7th Edition. The McGraw - Hill Companies. (2003); PP.304.

20. Campbell, Colin K, Elizabeth M, Johnson and David W. Warnock. Identification of Pathogenic Fungi, 2nd ed.Chichester, West Sussex [u.a.]: Wiley-Blackwell, (2013).

21. Kaur R, Dhakad MS, Goyal R, Haque A, Mukhopadhyay G. Identification and Antifungal Susceptibility Testing of Candida Species: A Comparison of Vitek-2 System with Conventional and Molecular Methods. Journal of global infectious diseases. (2016); 8(4):139-146.

22. Shadomy S, Ingroff E, Cartwright RY. Laoratory studies with antifungal agenst : Suseptibility test and bioassays In:Manual of clinical microbiology. Lennette EH, Balows A, Hausler WJ, shadomy HJ. (eds)Am. Soci .Microbiol. 4th ed.ch.104. (1985).

23. NCCLS. M27-A2. In National Committee for Clinical Laboratory Standards. Reference method for broth dilution antifungal susceptibility testing of yeasts: proposed standard. (2002).

24. Ibrahim IM, Iftikhar M, Ali IM, Dheeb BI, Abbas QA, Ramizy A, Eisa MH , Aljameel AI. Antifungal activity of wide band gap Thioglycolic acid capped ZnS:Mn semiconductor nanoparticles against some pathogenic fungi .Materials Science and Engineering.(2017); C 73:665-669.

25. Khalaf HA, Mahdi MF, Abaas IS. Preliminary phytochemical and GC-MS analysis of chemical constituents of Iraqi Plantago lanceoleta L. AJPS. (2018); 18(2):114-121.

26. Magaldi S, Camero T. Susceptibilidad de Candida albicans 'in vitro' mediante los pozos de difusión. Bolet'in Venezolano de Infectolog'1a. (1997); 7:5-8.

27. AL-Taee QM. An Identificational Study of Candida spp. Yeast isolated from patients infected with oral candidiasis in mosul city and study the effect of mother's milk and aqueous extract of red tea on its production for some virulence factors.m.sc. Thesis, College of Science. University of Mosul. Iraq. (2013).

28. Bander KI, Mohammed SH, Thalij KM, Dheeb BI. Survey Study of the Allergic Fungi in Kirkuk Area and Use Molecular Detection for Identification. I J S: B A R. (2015); 19(1):383-397.

29. Cox SD, Mann CM, Markham JL, Bell HC, Gustafson JE, Warmington GR, Wyllie SG. The mode of antimicrobial action of the essential oil of Melaleuca alternifolia (tea tree oil). Journal of Applied Microbiology. (2000); 88(1), 170-175.

30. Hammer KA, Carson CF , Riley TV. Antifungal effects of Melaleuca alternifolia (tea tree) oil and its components on Candida albicans, Candida glabrata and Saccharomyces cerevisiae. Journal of Antimicrobial Chemotherapy. (2004); 53:1081-1085.

31. Ibrahim HI, Yehia MM. Cervico-Vaginal Candidiasis in married Women. Kirkuk University journal/ Scientific studies (KUJSS). (2017); 12(4):1992-0849. 
32. Nnaemeka O, Pauline U. Prevalence of vaginal candidiasis among pregnant women in Nnewi town of anambra state, Nigeria. An international multi-disciplinary journal, ethiopia. (2010); 4(4):539-548.

33. Glatthaar E, Cartwright RY, Kunz J. Vulvovaginitis-congresses. Vulvovaginitis-Round Table Discussion: Conference Proceedings, National Library of Australia.(1982); pp37.

34. Mbim EN, Mboto CI, George UE, et al. Prevalence of Vaginal Candidiasis among Female Students of a Hostel in the University of Calabar, Calabar. J. of Applied life Sciences International. (2017); 13(3):1-7.

35. Banno IS, Nakkash AF, Mizi'l SN. Isolation and Identification of Candida albicans from vagina and Study of some Virulance Factors.J. Baghdad of Science. (2010); 7(1): 1-8.

36. Zafar A, Jabeen K, Farooqi J. (Eds.). Practical guide and atlas for the diagnosis of fungal infections. (2017).

37. Kurtzman CP , Fell JW. The Yeasts, a taxonomic study. $4^{\text {th }}$ ed., Elsevier Science BV, the Netherland. (1998).

38. Mackenzie DWR. Serum tube identification of Candida albicans. J. Clin. Pathol. (1962); 15: 563-565.

39. Brito G, Inocêncio A, Querido S, Jorge A, Koga-Ito C. In vitro antifungal susceptibility of Candida spp. oral isolates from HIV positive patients and control individuals. Braz Oral Res. (2010); 25(1):28-33.

40. Devkatte AN, Zore GB, Karuppayil SM. Potential of plant oil inhibition of Candida albicans growth. FEMS Yeast Research. (2005); 5:867-873.

41. Godoy $\mathrm{P}$,Tiraboschi IN, Severo LC, et al. Species distribution and antifungal susceptibility profile of Candida spp. Bloodstream isolates .(2003).

42. Penfold AR, Grant R. The germicidal values of some Australian essential oils and their pure constituents, together with those for some essential oil isolates, and synthetics. Part III. J. R. Soc. New South Wales. (1925); 59:346-349.

43. Carson CF, Riley TV. Antimicrobial activity of the major components of the essential oil of Melaleuca alternifolia. J. Appl. Bacteriol. (1995); 78:264-269.

44. Christoph F, Kaulfers PM, Stahl-Biskup E. A comparative study of the in vitro antimicrobial activity of tea tree oils s.l. with special reference to the activity of $\beta$-triketones. Planta Med. (2000); 66:556-560.

45. Olama Z, Holail H, Makk S. Antifungal effect of some plant oils against some oral clinical isolates of Candida albicans in Lebanese community. The online journal of science and technology. (2013); 3(3): 2539.

46. Hammer KA, Carson CF, Riley TV. Influence of organic matter, cations and surfactants on the antimicrobial activity of Melaleuca alternifolia (tea tree) oil in vitro. Journal of Applied Microbiology. (1999); 86,446-452.

47. Uribe S, Ramirez J , Peña A. Effects of $\beta$-pinene on yeast membrane functions. Journal of Bacteriology. (1985); 161:1195-1200.

48. Carson CF, Mee BJ, Riley TV. Mechanism of Action of Melaleuca alternifolia (Tea Tree) oil on Staphylococcus aureus determined by time-kill, lysis, leakage, and salt tolerance assays and electron microscopy. Antimicrob Agents Chemother. (2002); 46(6):1914-1920.

49. Dheeb BI, Al-dujayli SMA, Ibrahim IM, Abbas QA. Study the Antifungal Activity of ZnS:Mn Nanoparticles Against Some Isolated Pathogenic Fungi (2019). Journal of Physics: Conference Series. (2019); 1178: 46-52.

50. Dheeb BI, Al-Mudallal NH, Salman ZA, Ali M. The Inhibitory Effects of Human, Camel and Cow's Milk against Some Pathogenic Fungi in Iraq. Jordan Journal of Biological Sciences. (2015); 8(2): 89 - 93. 